\title{
Creating a Trauma-Informed Community Through University-Community Partnerships: An Institute Agenda
}

\author{
John M. Keesler \\ Susan A. Green \\ Thomas H. Nochajski
}

\begin{abstract}
The impact of trauma on wellness has been identified as a community health crisis. The alliance of universities and communities is a plausible response to address the scope of the problem given their wealth of resources. The Institute on Trauma and Traumainformed Care (ITTIC) is an exemplar of a university-community partnership and unique approach that has fostered a common language within and between organizations to foster at the community level an awareness and understanding of trauma. The present article provides an overview of university-community partnerships and their importance to social work practice. It describes the formation of the Institute and discusses its model and contributions to the local community and abroad. The implications of ITTIC for the School, University and community are discussed. An iterative process that includes active engagement, evaluation, and reflection, is recommended for the integration and advancement of trauma-informed care through university-community partnerships.
\end{abstract}

Keywords: University-community partnerships; trauma; trauma-informed care

Universities are uniquely situated to address the social needs of their surrounding communities, due, in part, to their civic engagement as well as the intersection of teaching, research, and service (Buys \& Bursnall, 2007; Maurrasse, 2002). University-community partnerships are one way in which academic institutions can fulfill this responsibility. The present article provides an overview of university-community partnerships as represented in the literature and highlights their relevance to social work. The Institute on Trauma and Trauma-informed Care at the University at Buffalo, New York, is then described as an exemplar for university-community partnerships, particularly as it addresses the community's need to become trauma-informed. The development of the Institute, as well as its efforts, contributions, and future directions are discussed.

\section{University-Community Partnerships}

University-community partnerships foster the development of relationships across systems and the mobilization of pooled resources through collaborative initiatives. While universities provide excellence in research and education, community partners provide practice knowledge and a natural setting with community members. Together, these partnerships can "advance practice to research and research to practice" (Dulmus \& Cristalli, 2012, p.195) as they bridge the gaps between research and practice, and, the classroom and real-world practice (Institute of Medicine, 2001; McCaslin \& Barnstable, 2008; Mullen, Bledsoe, \& Bellamy, 2007). Further, the information exchanged between

John M. Keesler, PhD, LMSW, is Assistant Professor, School of Social Work, Indiana University, Bloomington, IN, 47401. Susan A. Green, LCSW, is Clinical Associate Professor, School of Social Work, University at Buffalo, Buffalo, NY 14214. Thomas H. Nochajski, PhD, is research Professor, School of Social Work, University at Buffalo, Buffalo, NY 14214.

Copyright @ 2017 Authors, Vol. 18 No. 1 (Spring 2017), 39-52, DOI: 10.18060/21298 (cc) BY This work is licensed under a Creative Commons Attribution 4.0 International License. 
the academy and the social service sector can: (a) promote professional development; (b) establish and strengthen meaningful relationships; (c) foster social change efforts; and, (d) enable better client outcomes (Allen-Meares, 2008; Miller \& Hafner, 2008; Van de Ven \& Johnson, 2006).

University-community partnerships represent diverse collaborations with a range of activities and levels of engagement (Strier, 2014). The diversity is highlighted in the literature which includes partnerships aimed at: social work curriculum development (Lewis, Kusmaul, Elze, \& Butler, 2016), low-income senior housing (Perry et al., 2015); homelessness (Patterson, Cronley, West, \& Lantz, 2014), nonprofit capacity building (Kindred \& Petrescu, 2015); child protection and family violence (Fantuzzo, Mohr, \& Noone, 2000), and the advancement of research in human service organizations (Dulmus \& Cristalli, 2012).

University-community partnerships can be vulnerable to various challenges given the potential for an imbalance of power and differences in expectations (Dempsey, 2010; Kindred \& Petrescu, 2015). However, such challenges can be minimized through shared decision-making, clearly defined roles, and the articulation of specific goals (Miller \& Hafner, 2008). In addition, transparency and the desire to learn from each other can foster trust, collaboration, and a shared sense of capacity and influence (Miller \& Hafner, 2008). These characteristics, centered on personal relationships, can lead to successful partnerships (Bringle \& Hatchner, 2002; McCaslin \& Barnstable, 2008).

\section{University-Community Partnerships, Social Work \& Trauma}

University-community partnerships can be integral to social work practice, education, and research (Dentato, Craig, \& Smith, 2010; Lewis et al., 2016). According to the preamble of the National Association of Social Workers' (NASW) Code of Ethics:

The primary mission of the social work profession is to enhance human wellbeing...with particular attention to [those]...who are vulnerable, oppressed, and living in poverty. A historic and defining feature of social work is the profession's focus on individual well-being in a social context and the well-being of society. Fundamental to social work is attention to the environmental forces that create, contribute to, and address problems in living.... Social workers also seek to promote the responsiveness of organizations, communities, and other social institutions to individuals' needs and social problems. (NASW, 2008, para. 1-2)

Trauma, although not explicitly noted in the preamble, is often at the intersection of vulnerability, oppression and poverty - dimensions of the human experience that are critical to social work. Over the past two decades, the complexities of trauma and potentially traumatic events have been illuminated, particularly given their association with health-compromising behaviors, disease, and what has been identified as a "health crisis" (Larkin, Felitti, \& Anda, 2014). Trauma-informed care has emerged as a systems-based response to trauma and trauma sequelae in order to create organizational environments that recognize the impact of trauma, promote healing, and avoid retraumatization (Butler, Critelli, \& Rinfrette, 2011; Harris \& Fallot, 2001). The Institute on Trauma and Traumainformed Care is an exemplar for how university-community partnerships can embrace the 
mission of social work with a particular focus on a community's need to become traumainformed.

\section{The Institute on Trauma and Trauma-Informed Care: Conceptualization and Inception}

The Institute on Trauma and Trauma-Informed Care (ITTIC) was established in 2011 by a clinical professor and a research professor in the School of Social Work at the University at Buffalo as a center for university-community partnerships that focus on consultation, collaboration, training, evaluation and research. The Institute developed in response to an advancing global awareness of the prevalence and impact of trauma (Mills et al., 2011) and the needs of the surrounding community. The foundation of ITTIC is comprised of the five principles of trauma- informed care: choice, collaboration, empowerment, safety, and trustworthiness (Harris \& Fallot, 2001). The mission of ITTIC is to foster a community-wide understanding of "what it means to be...trauma-informed..., [to] identify [and address] the need for trauma-informed change..., and [to] take necessary steps to integrate and sustain these changes over the long term" (Richardson, Coryn, Henry, Black-Pond, \& Unrau, 2012, p.179). The Institute is housed within the Buffalo Center for Social Research (BCSR) and complements the School's trauma-informed and human rights curriculum.

A Community in Need. ITTIC is nestled in a university campus that is situated in a community of approximately 264,000 residents that is marked by poverty, increasing violence, and changing demographics. Approximately 39\% of the population is African American and $11 \%$ is Hispanic/Latino (U.S. Census Bureau, 2010). About half of all residents are "doing poorly or struggling economically" with $43 \%$ of individuals having an income of $\$ 25,000$ or less and about $43 \%$ of children living in poverty (University at Buffalo Regional Institute, 2014a, 2014b, p.4). Poverty rates are influenced by regional job loss; for example, 20,000 jobs were lost between 2008 to 2009. In addition, 1 out of every 100 individuals in the community is a victim of a violent crime (not including theft or breaking and entering) and the rate of crime continues to increase. The needs of the community are compounded by gaps in psychiatric and medical services as well as changing demographics, including the annual resettlement of approximately 1,500 refugees (University at Buffalo Regional Institute, 2014a, 2014b). Low-income urban areas, like the respective community, have been associated with increased risk for trauma due to violence, drug activity, incarceration, and victimization. African Americans are disproportionately at increased risk for lifetime exposure to trauma (Kiser, Donohue, Hodgkinson, Medoff \& Black, 2010). As a social work institute focused on community collaboration, the placement and mission of ITTIC are most appropriate.

\section{Toward the Creation of a Trauma-informed Community}

ITTIC was established in a time and environment that was "ready for it." Across the United States, initiatives and policies to support trauma-informed practices were well underway (Cooper, Masi, Dababnah, Aratani, \& Knitzer, 2007). For example, as early as 2005, Illinois, Massachusetts, and Oklahoma had passed legislation and implemented

collaborative efforts to foster the integration of trauma-informed practices in child welfare 
systems, schools, and behavioral health. Similarly, efforts were underway within New York State through the Community Health Care Association of New York State and in collaboration with the National Traumatic Stress Network, to promote trauma-informed care within various medical centers, family and children's services, and through training institutes.

More proximally, the University of Buffalo School of Social Work, with which ITTIC is affiliated, was pursuing its re-accreditation. As the School engaged in this process, it considered the needs of the community and the status of TIC within the surrounding community-based organizations. The founding co-directors of the Institute assisted the School in developing an assessment tool that would facilitate a community evaluation. The School had a strong presence in the community through well-established field placements and numerous alumni working in the community. This presence fostered openness among community organizations to the administration of the measure. The School gathered and analyzed the data, and subsequently disseminated their findings to the community, which sparked an interest among organizations for more information on TIC.

Concurrently, as the School established a new trauma-informed curriculum, the community started a trauma coalition in which one of the Institute's co-directors played an integral role. In response to the community's desire for more knowledge and training, ITTIC was created. Among the first initiatives of the new Institute was the procurement of a Substance Abuse and Mental Health Services Administration (SAMHSA) train-thetrainer grant. As information about the training and ITTIC spread, the Institute began to receive requests from organizations for training. Such requests were, in part, influenced by current students in their field placements and a strong presence of School alumni, many of whom were among the first to request training. Notably, although the Institute initially had few resources, many of the early trainings and consultations were provided free-of-charge. Pro bono work further fostered relationships between the ITTIC and the community. It became evident that the Institute was committed to its work and invested in the community.

ITTIC used a formative process during its development, beginning with the support of the School's Dean, including the allocation of physical space in the School's research center. The first year for the Institute was critical to establishing a community presence and involved strategic tasks such as developing an online presence; establishing an advisory council of local, national and international expertise; crafting a strategic plan; creating a field placement for MSW interns; and generating initial revenue (e.g., SAMHSA training grant).

As the work of the Institute continued to expand, the co-directors sought consultation from top administrators in local agencies to help create a strategic plan. Similarly, ITTIC established an expert advisory panel of lead experts in the field of trauma and TIC to provide the Institute with advisement. Over the first year, the co-directors met biweekly, and had monthly meetings with the director of the BCSR. In addition, bimonthly meetings were held with various community members and recent graduates to help inform the Institute around priorities for engaging with the community. ITTIC shared information and literature (e.g. impact of trauma, understanding TIC, etc.) with community members and encouraged them to pass it along to others. 


\section{Collaboration: A Key Principle of TIC and ITTIC's Operation}

ITTIC embraces a total approach when working with community partners. The Institute assists organizations with the adoption and integration of trauma-informed care by working with them to identify their readiness for change, while assessing their resources (e.g., clinical sophistication) and supporting the development of sustainable strategies to foster change at the organizational level (Brown, Baker, \& Wilcox, 2012; Hummer, Dollard, Robst, \& Armstrong, 2010). The principles of trauma-informed care are enacted within the Institute's daily operations and its collaborations such that engagements with community partners become exemplars of trauma-informed practices.

By "modeling the model," members from ITTIC initiate a relationship with organizations that is based on trustworthiness and fosters emotional safety. Members extend themselves to the organizations by their willingness to meet with them in person, visiting the agency, and making themselves available for ongoing consultation via phone and/or in person. During the initial phases of partnership, it is not uncommon for ITTIC to provide the organization with references from previous partners. In addition, materials, resources and information (e.g., infographics, impact of trauma, etc.) are provided to the organization to help them make informed decisions about what makes most sense for them and how they would like to proceed. Partnerships begin with open dialogue regarding what the organization is looking for and different options that the Institute can provide to them depending on what makes most sense for the organization. Together, the organization and ITTIC work together to develop a strategic plan that is tailored to the organization's goals and the resources that they have available to them. Through ongoing communication and routine contact with a point person(s) at the organization, members of the Institute provide updates, have team meetings to monitor progress on the work plan/timeline, and maintain flexibility to feedback throughout the process. While ITTIC acknowledges its expertise in trauma and TIC, it also recognizes and upholds the expertise of agency staff regardless of their position or experience. The Institute maintains a stance of not telling organizations what to do, but rather, working with the organizational team to operationalize what TIC looks like in their role and in their agency.

The process for organizations to become trauma-informed involves a cultural shift "structured around the presumption that everyone in the agency (from clients through agency management) may have been directly or indirectly exposed to trauma" (Wolf, Green, Nochajski, Mendel, \& Kusmaul, 2014, p.111). Thus, the Institute seeks to ensure that an organization, from executive management to clients, as well as all policies, practices and procedures, are trauma-informed (Harris \& Fallot, 2001). The inclusion of employees is critical - they translate policies into practices with clients - yet they are often overlooked regarding trauma-informed care (Bowen, Privitera, \& Bowie, 2011; Keesler, 2016; Wolf et al., 2014). ITTIC also explores the ways in which organizations already exemplify trauma-informed practices with clients as trauma-informed practices are frequently used yet rarely identified as such (Wolf et al., 2014).

\section{Training - A Critical Element}

Training is central to ITTIC's mission as it is a critical component for agencies seeking 
to implement trauma-informed care (Brown et al., 2012). Although many trauma-informed initiatives "lack theory-based comprehensive staff trauma training models that agencies can adopt system-wide as a way to implement TIC" (Brown et al., 2012, p.508), the Institute uses a user-friendly training curriculum comprised of fundamental trauma knowledge (e.g., definition of trauma and its biopsychosocial implications, triggers, retraumatization, vicarious traumatization) and the principles of trauma-informed care (e.g., conceptualization of principles, their importance, and their implementation). The training fosters a perceptual and attitudinal shift as participants are taught to approach trauma as a universal precaution (i.e., each person is interacted with as if they have experienced trauma) and to ask clients "What has happened to you?" rather than "What is wrong with you?" (Bloom, 1994).

The structure and content of the training is malleable to organization-specific wants and needs, and is often influenced by a reciprocal process of evaluation and training, largely consistent with translational research (Rubio et al., 2010). The Institute works with community partners based upon their needs and resources, and considers what makes most sense at that time. Thus, agencies get support (i.e., consultation/training/evaluation) that is personalized. In addition, baseline evaluations provide a critical understanding of an organization's current functioning from which the Institute can tailor the initiative and ascertain the initiative's impact through pre-/post-assessments and analyses (Hummer et al., 2010). This approach fosters the likelihood that the community partner will find the support useful and relevant, while increasing buy-in from those involved. In addition, ITTIC assists organizations in identifying and training "trauma champions" as a means of fostering the integration of trauma-informed care through a train-the-trainer model and as an ongoing internal support (Brown et al., 2012; Brown, Harris, \& Fallot, 2013; Henry et al., 2011).

\section{Growth and Advancement}

Over the course of five years, ITTIC has expanded its assets and impact in various ways. In addition to augmenting its advisory panel with national experts and pool of affiliates, the Institute has established an operating budget of self-sufficiency, expanded its capacity as a designated field placement for MSW students, as well as independent studies and research internships for PhD students. ITTIC has created a well-established presence within the community and demonstrated the versatility of trauma-informed care through its work with more than 20 local agencies and organizations in children's mental health and residential services; adult behavioral health; crisis services; refugee, asylee and immigrant services; military veteran services; and, the criminal justice system (Bloom \& Sreedhar, 2008). In addition, more than 10 students have completed field placements at ITTIC where they have been immersed in trauma-informed care. As students graduate and become employees within community organizations, they have the potential to further the work and connections of the Institute while promoting trauma-informed care. 
ITTIC has expanded its community influence through local think-tanks around trauma and trauma-informed care. In addition, it provides leadership and administrative support to the Trauma-Informed Community Initiative of Western New York (TICI). Together, they developed a community action plan to "lead and assist organizations, individuals, and communities through the mobilization of resources in education, prevention, and response to the multi-dimensional aspects of trauma as a root cause of our growing public health crisis" (University at Buffalo School of Social Work, 2016, para. 1). Grand rounds are hosted throughout the year to provide regional trainings and presentations on topics related to trauma and trauma-informed care.

The Institute has extended its influence beyond the local community to the state, national, and international levels. Through funded collaborations with the State Department of Health AIDS Institute and the State Office of Alcohol and Substance Abuse Services, ITTIC has engaged in partnerships focused on training individuals who will serve as champions across the State. The Institute has developed Trauma Talks, an online podcast series of interviews with service providers and survivors about strength, resilience, and trauma-informed approaches in the healing process for trauma. In addition, ITTIC and its affiliates continually present at agencies and universities, as well as national and international conferences such as the Society for Social Work Research, the Council on Social Work Education, and the International Congress on Law and Mental Health (e.g. Heagle, Green, \& Peek, 2016; Keesler \& Green, 2014; Keesler \& Nochajski, 2016; Nochajski \& Hales, 2015).

The Institute's use of Harris and Fallot's principle-based model has afforded opportunities for the development and validation of an instrument to measure traumainformed care within organizational culture which has largely been lacking (Brown et al., 2013; Clark et al., 2008; Hendricks, Conradi, \& Wilson, 2011; Kusmaul, Wilson, \& Nochajski, 2015). The development of such a measure presents the opportunity for comparative analyses within and among organizations, and the foundation for future work, for example, associations between trauma-informed care and agency/client outcomes (e.g., behavioral and psychiatric progress, injuries, staff retention). Such research is a critical next step in advancing trauma-informed practices (Brown et al., 2012).

Emergent and critical research surrounding TIC has come forth through the work of the Institute and its affiliates. Kusmaul et al. (2015) identified a high correlation among the five principles of TIC (Harris \& Fallot, 2001) thus suggesting the integral interrelationship between the principles as well as the possibility of a unidimensional construct. In addition, they noted an association between employees' education and position within an organization with their perceptions of TIC . Higher education and higher ranked personnel (e.g., administration) were associated with more favorable ratings of TIC. Keesler and Isham (2017) identified the feasibility of integrating TIC within the context of services for individuals with intellectual and developmental disabilities. Findings suggested a positive association between TIC and staff satisfaction, restraint reduction, and behavioral improvement among individuals with disabilities. This research was the first study of its kind within the peer-reviewed body of literature on intellectual and developmental disabilities. Subsequent research has identified a positive association between TIC training and increased satisfaction among human service staff (Hales et al., 2016). Following an 
agency-wide initiative to integrate TIC, post-test results identified approximately $10 \%$ to $16 \%$ increases in staff satisfaction with delivery of services, relationships with management, and connections and satisfaction with the workplace (Hales et al., 2016). In addition, Keesler (2016) noted the predictive nature of TIC and staff members' professional quality of life. Organizational environments that demonstrated greater presence of choice, collaboration, empowerment, safety, and trustworthiness, predicted greater satisfaction and lower burnout among workers. It is the authors' understanding that this is the first time TIC has been directly linked with staff outcomes.

\section{Differentiating Levels of Trauma Services}

Through its work, ITTIC has also identified and differentiated three levels of trauma services: (1) trauma-informed, (2) trauma-sensitive, and (3) trauma-specific. This perspective mirrors prevention and health promotion models that recognize universal, secondary, and tertiary levels of intervention (Skybo \& Polivka, 2007). In addition, the trilevel perspective provides clarity for providers and appropriately frames the primary work of the Institute in relation to other possibilities for the care and treatment of individuals who have experienced trauma.

At the first level, trauma-informed practices are anchored in choice, collaboration, empowerment, safety, and trustworthiness for everyone (Harris \& Fallot, 2001). Being trauma-informed considers: (a) where and when services are offered; (b) attentiveness to signs of discomfort among clients and staff; (c) perception of discomfort in a traumainformed way; (d) providing clear information about what will be done, by whom, when, why, and under what circumstances; (e) provision of clear and appropriate messages regarding rights and responsibilities to clients and staff; (f) cultivating an atmosphere of working "with" rather than doing "to" or "for"; (g) providing an atmosphere that allows people to feel validated and affirmed with each and every contact at the agency; (h) paying attention to what works and what does not; and, (i) a deliberate use of non-problem focused language.

Trauma-sensitive is the second level of trauma services. Being trauma-sensitive involves the decision to address trauma and is exemplified through the use of trauma screening tools/evaluations and considers the procedures and process of providing services to clients. A deliberate effort is made in allocating time to: (a) witness the impact the work may have on staff; (b) promote self-care practices (e.g., having a venue for staff to decompress, debrief, and rebuild); and, (c) modifying intake, supervisory sessions, and procedures that may be intrusive.

The third level of trauma services is trauma-specific. Trauma-specific refers to trauma treatments that have been researched and are evidenced-based or, at least, promising practices. Such interventions are conducted by clinicians trained in the specific modality. Trauma-specific interventions include cognitive processing therapy, trauma-focused cognitive behavior therapy, crisis intervention stress debriefing (CISD), eye movement desentization reprocessing (EMDR), and prolonged exposure (PE). Most of the treatments for trauma that have been categorized as evidence-based or promising have specifically treated PTSD. 


\section{Impact of Institute on School of Social Work}

ITTIC has had a notable impact on the University of Buffalo School of Social Work within a relatively brief period of time. First, the Institute has served as a champion of and consultant on the trauma-informed perspective for the School. The directors of ITTIC have helped to train the School's faculty and staff on trauma-informed care and have facilitated changes within the School toward more trauma-informed practices. Secondly, the Institute has strengthened the School's portfolio. Through service, teaching and evaluation, ITTIC has generated additional revenue for the School, has made contributions to the literature through its emerging publications, and has helped faculty to define their roles within the School as leaders. Thirdly, the School has become more prominent in the community. As trauma-informed care has become a "hot topic" locally, regionally, and nationally, ITTIC's work has helped strengthen community relations and position the School as a strong partner for collaboration. Fourthly, ITTIC has become a model for the perspective of an institute within the University. Because of the distinguished identity of the ITTIC in the community, the University has begun to look to the Institute and the School for leadership in institute development. Lastly, ITTIC has helped the School with recruitment of students and faculty. With trauma and trauma-informed care at the forefront of behavioral health, the Institute has attracted not only students who seek to learn more about trauma and trauma-informed care through applied experience, but also faculty members who seek to partner on grants and research opportunities given the well-established community relationships between ITTIC and the community.

\section{Directions for Future Work}

As ITTIC continues to envision a trauma-informed community, it strives to increase its influence and sustainability through an expansion of community partnerships, presentations, publications, and funding. The directors and affiliates continue to learn about the process of becoming trauma-informed from each community partner and about the nuances of trauma-informed care with specialized populations. The need to better understand how TIC is implemented within an organization and viewed by service providers is recognized by the Institute and is supported by research (Kusmaul et al., 2015).

\section{Conclusion}

University-community partnerships can be seen as "joint ventures [with] opportunities to achieve different goals" (Strier, 2014, p.155). However, for ITTIC and its community partners, the goal has been mutual: to infuse trauma-informed care within service delivery. This is a unique consideration that has strengthened the Institute as a visible and viable resource for the community, School, and University. Good relationship-building and its components are inherent in trauma-informed care. As such, the product has become much of the process for the Institute. Kindred and Petrescu (2015) noted:

Communication and relationship building [are] an important aspect to community collaborations, and to understanding and potentially improving the process is just as important as delivering outcomes. Paying attention to process and relationship building will ultimately impact future community collaboration efforts between 
universities and nonprofits and may potentially lead to even better outcomes than participants initially expect. (p. 840)

The directors and affiliates of the Institute continue to learn about what it means to be trauma-informed and the process of becoming trauma-informed as it evolves through their work. While many people experience trauma and potentially traumatic events, far fewer are ever diagnosed with post-traumatic stress disorder (PTSD; Kessler, Sonnega, Bromet, Hughes, \& Nelson, 1995). However, the need to consider those who have not been diagnosed with PTSD yet have trauma symptoms remains, and a general awareness and understanding of trauma is warranted, thereby justifying the need to be trauma-informed. Thus, the establishment of a trauma-informed community through the adoption of a common language within and between organizations continues through the work of ITTIC, grounded in university-community partnerships.

\section{References}

Allen-Meares, P. (2008). Schools of social work contribution to community partnerships: The renewal of the social compact in higher education. Journal of Human Behavior in the Social Environment, 18, 79-100. doi: https://doi.org/10.1080/10911350802317194

Bloom, S. (1994). The sanctuary model: Developing generic inpatient programs for the treatment of psychological trauma. In M. B. Williams \& J. F. Sommer, Jr. (Eds.), Handbook of post-traumatic therapy: A practical guide to intervention, treatment, and research (pp. 474-493). Westport, CN: Greenwood Publishing.

Bloom, S. L., \& Sreedhar, S. Y. (2008). The Sanctuary Model of trauma informed organizational change. Reclaiming Children and Youth, 17(3), 48-53.

Bowen, B., Privitera, M. R., \& Bowie, V. (2011). Reducing workplace violence by creating healthy workplace environments. Journal of Aggression, Conflict and Peace Research, 3(4), 185-198. doi: https://doi.org/10.1108/17596591111187710

Bringle, R., \& Hatcher, J. (2002). Campus-community partnerships: The terms of engagement. Journal of Social Issues, 58, 503-516. doi: https://doi.org/10.1111/1540$\underline{4560.00273}$

Brown, S. M., Baker, C. N., \& Wilcox, P. (2012). Risking connection trauma training: A pathway toward trauma informed care in child congregate care settings.

Psychological Trauma: Theory, Research, Practice, and Policy, 4, 507-514.doi: https://doi.org/10.1037/a0025269

Brown, V. B., Harris, M., \& Fallot, R. (2013). Moving toward trauma informed practice in addiction treatment: a collaborative model of agency assessment. Journal of Psychoactive Drugs, 45(5), 386-393. doi: https://doi.org/10.1080/02791072.2013.844381

Butler, L. D., Critelli, F. M., \& Rinfrette, E. S. (2011). Trauma-informed care and mental health. Directions in Psychiatry, 31, 197-210.

Buys, N., \& Bursnall, S. (2007). Establishing university-community partnerships: 
Processes and benefits. Journal of Higher Education Policy and Management, 29, 73-86. doi: https://doi.org/10.1080/13600800601175797

Clark, C., Young, M. S., Jackson, E., Graeber, C., Mazelis, R., Kammerer, N., \& Huntington, N. (2008). Consumer perceptions of integrated trauma informed services among women with co-occurring disorders. The Journal of Behavioral Health Services \& Research, 35(1), 71-90. doi: https://doi.org/10.1007/s11414-007-9076-0

Cooper, J. L., Masi, R., Dababnah, S., Aratani, Y., \& Knitzer, J. (2007). Strengthening policies to support children, youth, and families who experience trauma. National Center for Children in Poverty: Columbia University.

Dempsey, S. E. (2010). Critiquing community engagement. Management Communication Quarterly, 24, 359-390. doi: https://doi.org/10.1177/0893318909352247

Dentato, M. P., Craig, S. L., \& Smith, M. S. (2010). The vital role of social workers in community partnerships: The alliance for gay, lesbian, bisexual, transgender and questioning youth. Child and Adolescent Social Work Journal, 27(5), 323-334. doi: https://doi.org/10.1007/s10560-010-0210-0

Dulmus, C. N., \& Cristalli, M. E. (2012). A university-community partnership to advance research in practice settings: The HUB research model. Research on Social Work Practice, 22(2), 195-202. doi: https://doi.org/10.1177/1049731511423026

Fantuzzo, J. W., Mohr, W. K., \& Noone, M. J. (2000). Making the invisible victims of violence against women visible through university/community partnerships. Journal of Aggression, Maltreatment \& Trauma, 3(1), 9-23. doi: https://doi.org/10.1300/J146v03n01 02

Hales, T., Green, S. A., Lunsford, C., Hitzel, H., Woike-Ganga, E., \& Nochajski, T. H. (2016). Trauma-informed care and staff satisfaction. Poster presented at the Society for Prevention Research, San Francisco, CA.

Harris, M. E., \& Fallot, R. D. (2001). Using trauma theory to design service systems. Jossey-Bass, San Francisco, CA.

Heagle, E., Green, S. A., \& Peek, S. (2016, June). Trauma-informed care: The use of the podcast series Trauma Talks: Rising from the ashes to promote resiliency. Poster presented at Trauma Talks Conference, Toronto, Ontario, Canada.

Hendricks, A., Conradi, L., \& Wilson, C. (2011). Creating trauma informed child welfare systems using a community assessment process. Child Welfare, 90(6), 187-205.

Henry, J., Richardson, M., Black-Pond, C., Sloane, M., Atchinson, B., \& Hyter, Y. (2011). A grassroots prototype for trauma informed child welfare system change. Child Welfare, 90(6), 169-186.

Hummer, V. L., Dollard, N., Robst, J., \& Armstrong, M. I. (2010). Innovations in implementation of trauma informed care practices in youth residential treatment: A curriculum for organizational change. Child Welfare, 89(2), 79-95.

Institute of Medicine. (2001). Crossing the quality chasm: A new health system for the 
21st century. Washington, DC: National Academies Press.

Keesler, J., \& Green, S. A. (2014, October). Advancing a national initiative to become trauma-informed through university-community partnerships. Paper presented at Council on Social Work Education Annual Meeting University-Community Partnerships Track, Tampa, FL.

Keesler, J., \& Nochajski, T. H. (2016, January). Advancing trauma-informed care research: The influence of department affiliation and demographics on staff perception. Poster presented at the Society for Social Work Research Annual Conference, Washington, D. C.

Keesler, J. M., \& Isham, C. (2017). A trauma-informed day program: An initial conceptualization and preliminary assessment. Journal of Policy and Practice in Intellectual Disabilities, 14(2), 164-175.

Keesler, J. M. (2016). An evaluation of individual and organizational factors in predicting professional quality of life among direct support professionals in intellectual and developmental disability services. (Dissertation). University at Buffalo, Buffalo, NY.

Kessler, R. C., Sonnega, A., Bromet, E., Hughes, M., \& Nelson, C. B. (1995). Posttraumatic stress disorder in the National Comorbidity Survey. Archives of General Psychiatry, 52(12), 1048-1060. doi: https://doi.org/10.1001/archpsyc.1995.03950240066012

Kindred, J., \& Petrescu, C. (2015). Expectations versus reality in a university-community partnership: A case study. Voluntas, 26, 823-845. doi: https://doi.org/10.1007/s11266-014-9471-0

Kiser, L. J., Donohue, A., Hodgkinson, S., Medoff, D., \& Black, M. M. (2010). Strengthening family coping resources: The feasibility of a multifamily group intervention for families exposed to trauma. Journal of Traumatic Stress, 23(6), 802806.

Kusmaul, N., Wilson, B., \& Nochajski, T. (2015). The infusion of trauma-informed care in organizations: Experience of agency staff. Human Service Organizations: Management, Leadership \& Governance, 39(1), 25-37. doi: https://doi.org/10.1080/23303131.2014.968749

Larkin, H., Felitti, V. J., \& Anda, R. F. (2014). Social work and adverse childhood experiences research: Implications for practice and health policy. Social Work in Public Health, 29(1), 1-16. doi: https://doi.org/10.1080/19371918.2011.619433

Lewis, L. A., Kusmaul, N., Elze, D., \& Butler, L. (2016). The role of field education in a university-community partnership aimed at curriculum transformation. Journal of Social Work Education, 52(2), 186-197.

Maurrasse, D. J. (2002). Higher education-community partnerships: Assessing progress in the field. Nonprofit and Voluntary Sector Quarterly, 31, 131-139. doi: https://doi.org/10.1177/0899764002311006 
McCaslin, R., \& Barnstable, C. L. (2008). Increasing geriatric social work content through university-community partnerships. Gerontology \& Geriatrics Education, 29, 1-18. doi: https://doi.org/10.1080/02701960802074214

Miller, P., \& Hafner, M. (2008). Moving toward dialogical collaboration: A critical examination of a university-school-community partnership. Educational Administration Quarterly, 44, 66-110. doi: https://doi.org/10.1177/0013161X07309469

Mills, K. L., McFarlane, A. C., Slade, T., Creamer, M., Silove, D., Teesson, M., \& Bryant, R. (2011). Assessing the prevalence of trauma exposure in epidemiological surveys. Australian and New Zealand Journal of Psychiatry, 45, 407-415. doi: https://doi.org/10.3109/00048674.2010.543654

Mullen, E. J., Bledsoe, S. E., \& Bellamy, J. L. (2007). Implementing evidence-based social work practice. Research on Social Work Practice, 18, 325-338. doi: https://doi.org/10.1177/1049731506297827

National Association of Social Workers. (2008). Code of ethics of the National Association of Social Workers. Retrieved from http://www.socialworkers.org/pubs/code/code.asp

Nochajski, T. H., \& Hales, T. W. (2015, July). Evaluation as a tool for creating traumainformed systems. Poster presented at the XXXIV International Congress on Law and Mental Health, Vienna, Austria.

Patterson, D. A., Cronley, C., West, S., \& Lantz, J. (2014). Social justice manifest: A university-community partnership to promote the individual right to housing.

Journal of Social Work Education, 50(2), 234-246. doi: https://doi.org/10.1057/9781137289384.0016

Perry, T. E., Wintermute, T., Carney, B. C., Leach, D. E., Sanford, C., \& Quist, L. (2015). Senior housing at a crossroads: A case study of a university/community partnership in Detroit, Michigan. Traumatology, 21(3), 244-250. doi: https://doi.org/10.1037/trm0000043

Richardson, M. M., Coryn, C. L. S., Henry, J., Black-Pond, C., \& Unrau, Y. (2012). Developmental and evaluation of the trauma informed system change instrument: factorial validity and implications for use. Child and Adolescent Social Work Journal, 29, 167-184. doi: https://doi.org/10.1007/s10560-012-0259-Z

Rubio, D. M., Schoenbaum, E. E., Lee, L. S., Schteingart, D. E., Marantz, P. R., Anderson, K. E., ... \& Esposito, K. (2010). Defining translational research: Implications for training. Academic Medicine, 85(3), 470-475. doi: https://doi.org/10.1097/ACM.0b013e3181ccd618

Skybo, T., \& Polivka, B. (2007). Health promotion model for childhood violence prevention and exposure. Journal of Clinical Nursing, 16(1), 38-45. doi: https://doi.org/10.1111/j.1365-2702.2006.01621.x

Strier, R. (2014). Fields of paradox: University-community partnerships. Higher 
Education, 68(2), 155-165. doi: https://doi.org/10.1007/s10734-013-9698-5

United States Census Bureau. (2010). QuickFacts Buffalo City, New York. Retrieved from http://www.census.gov/quickfacts/table/PST045215/3611000

University at Buffalo Regional Institute. (2014a). Strengthening WNY's Safety Net: A Community Report City of Buffalo (East of Main Street). Retrieved from http://ubwp.buffalo.edu/ubri/wp-content/uploads/sites/3/2014/06/StrengtheningWNYs-Safety-Net-Buffalo-West.pdf

University at Buffalo Regional Institute. (2014b). Strengthening WNY's Safety Net: A Community Report City of Buffalo (West of Main Street). Retrieved from http://ubwp.buffalo.edu/ubri/wp-content/uploads/sites/3/2014/06/StrengtheningWNYs-Safety-Net-Buffalo-East.pdf

University at Buffalo School of Social Work. (2016). Trauma-informed community initiative of $W N Y$. Retrieved from https://socialwork.buffalo.edu/socialresearch/institutes-centers/institute-on-trauma-and-trauma-informedcare/community-partnerships-initiatives/trauma-informed-community-initiative.html

Van de Ven, A. H., \& Johnson, P. E. (2006). Knowledge for theory and practice. Academy of Management Review, 31(4), 802-821. https://doi.org/10.5465/AMR.2006.22527385

Wolf, M. R., Green, S. A., Nochajski, T. H., Mendel, W. E., \& Kusmaul, N. S. (2014). 'We're civil servants': the status of trauma informed care in the community. Journal of Social Service Research, 40(1), 111-120. doi: https://doi.org/10.1080/01488376.2013.845131

Author note: Address correspondence to: John M. Keesler, PhD, LMSW, School of Social Work, Indiana University, 1127 E. Atwater Ave., Bloomington, IN, 47401, 812855-2580, jkeesler@iu.edu 